\title{
Angiotensin II type I receptor expression in ovarian cancer and its correlation with tumour angiogenesis and patient survival
}

\author{
K Ino', K Shibata', H Kajiyama', E Yamamoto', T Nagasaka², A Nawa', S Nomura' and F Kikkawa' \\ 'Department of Obstetrics and Gynecology, Nagoya University Graduate School of Medicine, 65 Tsurumai-cho, Showa-ku, Nagoya 466-8550, Japan; \\ ${ }^{2}$ Division of Pathology/Clinical Laboratory, Nagoya University Graduate School of Medicine, Nagoya, Japan
}

Angiotensin II, a main effector peptide in the renin-angiotensin system, acts as a growth-promoting and angiogenic factor via type I angiotensin II receptors (AT,R). We have recently demonstrated that angiotensin II enhanced tumour cell invasion and vascular endothelial growth factor (VEGF) secretion via $A T_{1} R$ in ovarian cancer cell lines in vitro. The aim of the present study was to determine whether $A T_{1} R$ expression in ovarian cancer is correlated with clinicopathological parameters, angiogenic factors and patient survival. Immunohistochemical staining for AT, R, VEGF, CD34 and proliferating cell nuclear antigen (PCNA) were analysed in ovarian cancer tissues $(n=67)$. Intratumour microvessel density (MVD) was analysed by counting the CD34-positive endothelial cells. Type I angiotensin II receptors were expressed in $85 \%$ of the cases examined, of which $55 \%$ were strongly positive. Type I angiotensin II receptors expression was positively correlated with VEGF expression intensity and MVD, but not with histological subtype, grade, FIGO stage or PCNA labelling index. In patients who had positive staining for AT,R, the overall survival and progression-free survival were significantly poor $(P=0.041$ and 0.017 , respectively) as compared to those in patients who had negative staining for $A T_{1} R$, although $V E G F$, but not $A T_{1} R$, was an independent prognostic factor on multivariate analysis. These results demonstrated that $A T_{1} R$ correlated with tumour angiogenesis and poor patient outcome in ovarian cancer, suggesting its clinical potential for a novel molecular target in strategies for ovarian cancer treatment.

British Journal of Cancer (2006) 94, 552-560. doi: I0.1038/sj.bjc.660296I www.bjcancer.com

Published online 24 January 2006

(c) 2006 Cancer Research UK

Keywords: angiotensin II; AT, receptor; angiogenesis; ovarian cancer; VEGF; prognosis

Ovarian cancer is the leading cause of death from female genital malignancies despite significant advances in diagnosis and treatment (McGuire and Markman, 2003). Several clinicopathological parameters have been reported to be of prognostic significance in ovarian cancer, including disease stage, histological grade, histological subtype, residual tumour volume, presence of cytologically malignant ascites and response to chemotherapy (Omura et al, 1991; Chi et al, 2001). In addition to these established clinical parameters, the identification of biochemical or molecular markers more strictly related to intrinsic tumour cell behaviour in ovarian cancer and its characteristic progression pathway may be helpful in improving the survival of patients with this disease.

Angiotensin II, a multifunctional bioactive peptide in the reninangiotensin system (RAS), plays a fundamental role in controlling cardiovascular and renal homeostasis. Angiotensin II also acts as a potent growth factor not only for vascular smooth muscle cells, but also for certain cancer cell lines (Fujimoto et al, 2001; Muscella et al, 2002). In addition, angiotensin II stimulates angiogenesis via the upregulation of vascular endothelial growth factor (VEGF) (Le Noble et al, 1993; Chua et al, 1998; Pupilli et al, 1999; Tamarat

Correspondence: Dr K Ino; E-mail: kazuino@med.nagoya-u.ac.jp Received 29 July 2005; revised 30 November 2005; accepted 14 December 2005; published online 24 January 2006 et al, 2002). These cellular effects of angiotensin II are mostly mediated through specific G-protein-coupled $\mathrm{AT}_{1} \mathrm{R}$.

Recent studies have proposed the concept of a localized tissue RAS in various organs (Nielsen et al, 1995), and activation of the RAS has been demonstrated under neoplastic conditions (Inwang et al, 1997; Takeda and Kondo, 2001; Juillerat-Jeanneret et al, 2004). In the tumour-related RAS, angiotensin II is abundantly generated from angiotensin I by angiotensin-converting enzyme (ACE), and $\mathrm{AT}_{1} \mathrm{R}$ expression is generally upregulated. Previous studies showed that the angiotensin II- $\mathrm{AT}_{1} \mathrm{R}$ system is deeply involved in tumour growth, metastasis and angiogenesis in experimental animal models, suggesting a therapeutic potential of RAS blockade using an ACE inhibitor or $\mathrm{AT}_{1} \mathrm{R}$ blocker (Rivera et al, 2001; Yoshiji et al, 2001; Fujita et al, 2002; Miyajima et al, 2002; Egami et al, 2003; Uemura et al, 2003; Arrieta et al, 2005).

In gynaecological malignancies, prior studies at our laboratory demonstrated that angiotensin II stimulated in vitro cell proliferation, invasion, or VEGF secretion via $\mathrm{AT}_{1} \mathrm{R}$ in cervical cancer (Kikkawa et al, 2004; Suganuma et al, 2004), endometrial cancer (Watanabe et al, 2003) and choriocarcinoma (Ino et al, 2003). Recently, we were the first to show that $A_{1} R$ is expressed in human ovarian cancer cells and angiotensin II enhanced tumour cell invasion and VEGF expression/secretion via $\mathrm{AT}_{1} \mathrm{R}$ (Suganuma et al, 2005). Furthermore, we demonstrated that $\mathrm{AT}_{1} \mathrm{R}$ blocker suppresses angiogenesis and the peritoneal dissemination of ovarian cancer in a mouse model (Suganuma et al, 2005). These 
results prompted us to hypothesize that angiotensin II acts as an angiogenic and tumour-progressive factor for ovarian cancer, and that $\mathrm{AT}_{1} \mathrm{R}$ may have clinical potential as a novel molecular target or as a prognostic indicator in the treatment of ovarian cancer, as well as in other gynaecological malignancies.

Based on these findings, the present study examined the immunohistochemical expression of $\mathrm{AT}_{1} \mathrm{R}$ in ovarian cancer tissues to determine whether $\mathrm{AT}_{1} \mathrm{R}$ expression is correlated with clinicopathological factors or angiogenic parameters, including VEGF expression and intratumour microvessel density (MVD). Furthermore, we assessed whether $\mathrm{AT}_{1} \mathrm{R}$ correlates with the prognosis of ovarian cancer patients.

\section{MATERIALS AND METHODS}

\section{Reagents and antibodies}

Rabbit polyclonal antibody against $\mathrm{AT}_{1} \mathrm{R}$ (306) was purchased from Santa Cruz Biotechnology (Santa Cruz, CA, USA). Rabbit anti-human VEGF polyclonal antibody (A-20) was also purchased from Santa Cruz. Mouse monoclonal antibody against human CD34, a marker of endothelial cells, was obtained from Immunotech (Marseille, France). Antiproliferating cell nuclear antigen (PCNA) monoclonal antibody PC10 was purchased from Dako (Glostrup, Denmark).

\section{Patients and tissue samples}

Human epithelial ovarian cancer tissues $(n=67)$ were obtained from patients who underwent surgical treatment at Nagoya University Hospital between 1993 and 2002. Surgical treatment consisted of total abdominal hysterectomy and bilateral salpingooophorectomy, followed by surgical staging and/or debulking surgery (if necessary). All tissue samples were fixed in $10 \%$ formalin, embedded in paraffin, and routinely stained with haematoxylin and eosin for histological examination. The histological cell types and histological grade (tumour differentiation) were assigned according to the criteria of the World Health Organization (WHO) classification. Clinical staging was reviewed based on the International Federation of Gynecology and Obstetrics (FIGO) staging system. The patients received postoperative chemotherapy with platinum plus cyclophosphamide and doxorubicin (before 1997), or platinum plus paclitaxel (after 1997) for high-risk early stage (stage I with grade 3; stage IC; any stage II) or advanced diseases (stages III and IV). Tumour recurrence/progression was defined based on clinical, radiological or histological diagnosis. The use of tissue samples was approved by the Institutional Review Board (IRB) of Nagoya University Graduate School of Medicine and by individual patients, respectively.

\section{Immunohistochemistry}

Formalin-fixed, paraffin-embedded tissue sections were cut at a thickness of $4 \mu \mathrm{m}$. For heat-induced epitope retrieval, deparaffinized sections in $0.01 \mathrm{M}$ citrate buffer (Target Retrieval Solution $\mathrm{pH}$ 6.1, Dako) were treated three times at $90^{\circ} \mathrm{C}$ for $5 \mathrm{~min}$ using a microwave oven. Immunohistochemical staining was performed using the avidin-biotin immunoperoxidase technique (Histofine SAB-PO kit, Nichirei, Tokyo, Japan). Endogenous peroxidase activity was blocked by incubation with $0.3 \% \mathrm{H}_{2} \mathrm{O}_{2}$ in methanol for $15 \mathrm{~min}$, and nonspecific immunoglobulin binding was blocked by incubation with $10 \%$ normal goat serum for $10 \mathrm{~min}$. Sections were incubated at room temperature for $2 \mathrm{~h}$ with primary antibody (anti- $\mathrm{AT}_{1} \mathrm{R}$ at $1: 100$ dilution, anti-VEGF at $1: 200$, anti-CD34 at $1: 40$, anti-PCNA at $1: 40)$. The sections were rinsed and incubated for 30 min with biotinylated second antibody. After washing, the sections were incubated for $30 \mathrm{~min}$ with horseradish peroxidase- conjugated streptavidin, and finally treated with 3-amino-9ethylcarbazole (AEC) in $0.01 \% \mathrm{H}_{2} \mathrm{O}_{2}$ for $10 \mathrm{~min}$. The slides were counterstained with Meyer's haematoxylin. As a negative control, the primary antibody was replaced with normal rabbit IgG or mouse IgG at an appropriate dilution. As positive immunohistochemical controls, marked immunoreactivity of $\mathrm{AT}_{1} \mathrm{R}$ and VEGF in placental trophoblastic tissues was confirmed as reported previously (Shiraishi et al, 1996; Ino et al, 2003). The immunostaining intensity for $\mathrm{AT}_{1} \mathrm{R}$ and VEGF was scored semiquantitatively based on the percent positivity of stained cells on a three-tiered scale as follows: - , negative (no positive cells); + , focally or weakly positive ( $<50 \%$ positive cells); ++ , diffusely or strongly positive ( $>50 \%$ positive cells). In each case, at least three different areas were evaluated and the mean of the results was considered to be the expression intensity score. The staining procedure for each antibody was repeated twice, and it was confirmed that there was no difference in the staining intensity between the two experiments. The scoring procedure was carried out twice by two independent observers (each blinded to the other's score) without any knowledge of the clinical parameters or other prognostic factors. The concordance rate was over $95 \%$ between the observers. In the case of disagreement, the slides were reviewed simultaneously by these two observers, with another, different observer, who were seated together at a multiheaded microscope in order to resolve the difference of opinion.

\section{Evaluation of tumour angiogenesis and proliferation}

Tumour angiogenesis was assessed by counting the CD34-positive capillaries and small venules, according to the method of Weidner et al (1992). First, after scanning the immunostained section under a light microscope at low magnification $(\times 40$ and $\times 100)$, the area within the tumour having the highest number of distinct CD34staining microvessels ('hot spots') was selected. For the determination of intratumour MVD, all microvessels were counted within the neovascular hot spot under a light microscope at $\times 200$ magnification $(\times 20$ objective lens and $\times 10$ ocular lens). Two investigators independently evaluated tumour vascularity without any information about the clinicopathological features or expression scores for $\mathrm{AT}_{1} \mathrm{R}$ and VEGF. The average number of microvessels of the three $\times 200$ fields that were strictly confined to the hot spot area was recorded as the MVD, as described previously (Ueda et al, 1999).

To assess proliferation, sections were immunostained with the cellular proliferation marker PCNA as described previously (Thomas et al, 1995; Fujimura et al, 2000). The PCNA labelling index (PCNA LI) was defined as the number of tumour cells with nuclear PCNA immunostaining divided by the total number of tumour cells, and expressed as a percentage. A total of 1000 nuclei in the selected area were counted under a light microscope at high magnification $(\times 400$ fields) and the mean percentages were recorded as the PCNA LI.

\section{Statistical analysis}

Spearman's rank correlation test was performed to analyse the correlation between $\mathrm{AT}_{1} \mathrm{R}$ expression scores and various parameters. Fisher's exact test or chi-square $\left(\chi^{2}\right)$ test were also used to analyse the distribution of $\mathrm{AT}_{1} \mathrm{R}$-strongly positive cases, according to clinicopathological, angiogenic and proliferative features.

Overall survival (OS) was calculated from the date of diagnosis to the date of death, and progression-free survival (PFS) was calculated from the date of diagnosis to the date of progression/ recurrence or date of last follow-up. Survival analyses were performed according to the life tables method and according to the Kaplan-Meier method. Comparison of the survival between groups was performed with the log-rank test. Cox proportionalhazard analysis was used for univariate and multivariate analysis 

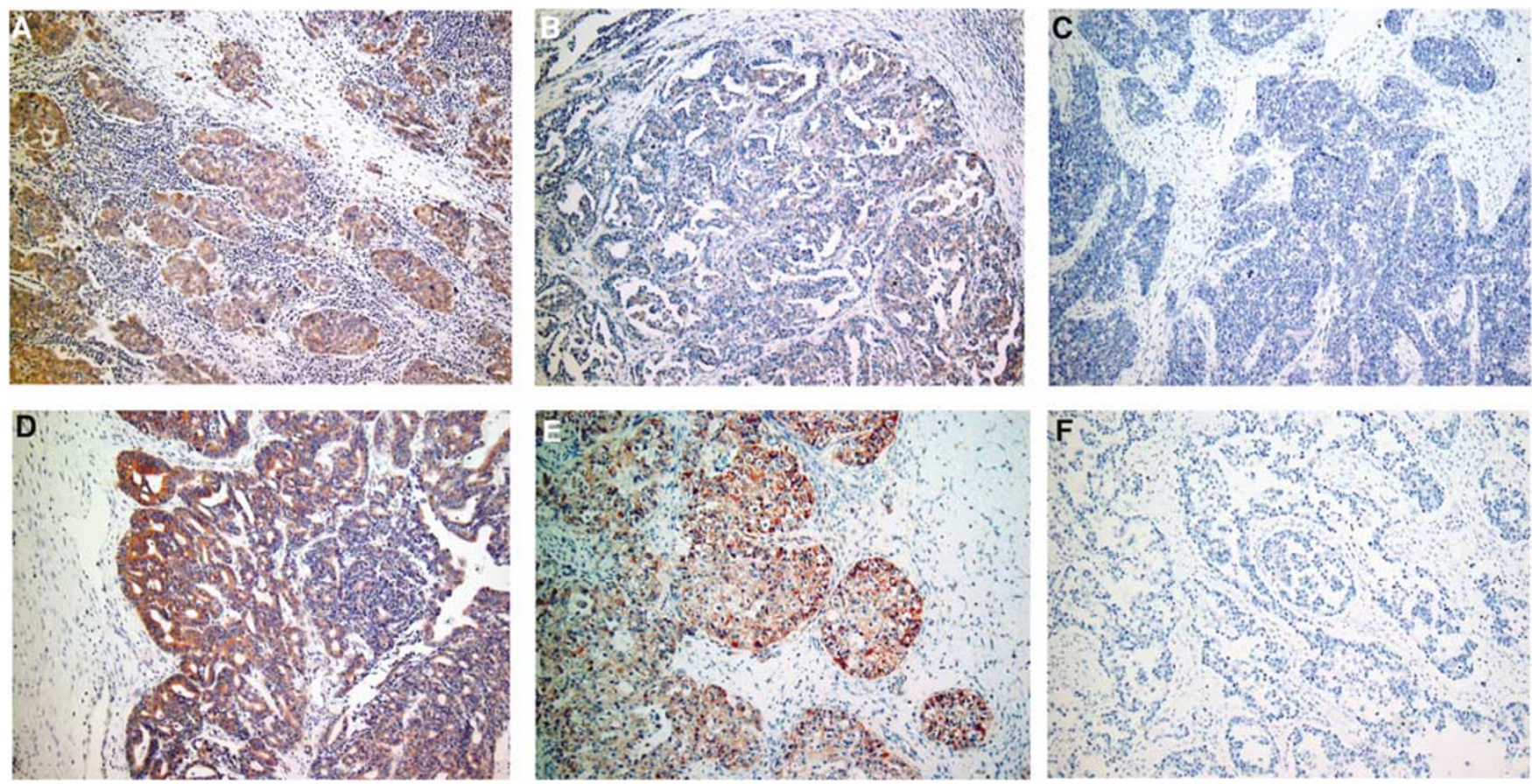

Figure I Representative immunohistochemical staining for AT, R in human ovarian cancer tissues. (A) Strongly positive; (B) weakly positive; (C) negative in serous adenocarcinoma; (D) strongly positive in endometrioid adenocarcinoma; (E) strongly positive in clear cell adenocarcinoma; (F) negative control. Original magnification, $\times 100$ in $(\mathbf{A}-\mathbf{F})$.

to explore the effect of variables on survival. The SAS software (SAS Institute Inc., Cary, NC, USA) was used for all statistical analyses and a $P$-value of $<0.05$ was considered significant.

\section{RESULTS}

\section{Immunohistochemical expression of $\mathrm{AT}_{1} \mathrm{R}$ in ovarian cancer tissues}

As shown in Figure 1, the immunoreactivity of $\mathrm{AT}_{1} \mathrm{R}$ was detected at variable levels, and was localized both on the membrane and in the cytoplasm of tumour cells. There was no immunoreactivity of $\mathrm{AT}_{1} \mathrm{R}$ in the tumour stroma. Of the 67 ovarian cancer specimens examined in this study, $\mathrm{AT}_{1} \mathrm{R}$ was detected in $57(85 \%)$ cases, of which $37(55 \%)$ were strongly positive. $\mathrm{AT}_{1} \mathrm{R}$-negative tumours were found in only 10 cases (15\%).

\section{Correlation of $\mathrm{AT}_{1} \mathrm{R}$ expression with clinicopathological, angiogenic and proliferative parameters}

The correlation of $\mathrm{AT}_{1} \mathrm{R}$ expression with clinicopathological, angiogenic and proliferative parameters was analysed in 67 ovarian cancer tissues. Type 1 angiotensin II receptors expression did not significantly correlate with the histological subtype, FIGO stage or histological grade (tumour differentiation) (Figure 2A-C). In contrast, the $\mathrm{AT}_{1} \mathrm{R}$ expression positively correlated with the VEGF staining scores (Figure 2D). Of the VEGF-strongly positive cases $(n=24), 20(83 \%)$ were $\mathrm{AT}_{1} \mathrm{R}$ strongly positive, while half $(n=9)$ of the VEGF-negative cases $(n=18)$ were $\mathrm{AT}_{1} \mathrm{R}$ negative (Figure 2D).

To determine the correlation between $\mathrm{AT}_{1} \mathrm{R}$ expression and tumour angiogenesis, we assessed the intratumour MVD by counting CD34-positive microvessels in the same series of ovarian cancer tissues $(n=67)$. Microvessel density ranged broadly from 20 to 150 (mean $=75.2$, median $=68$ ). Thus, we defined cases with
MVD number of more than 70 as high MVD $(n=32)$, while cases with MVD number of $<70$ were defined as low MVD $(n=35)$. Interestingly, the $\mathrm{AT}_{1} \mathrm{R}$ expression score positively correlated with $\mathrm{MVD}$, and $28(87.5 \%)$ of 32 high MVD cases were $\mathrm{AT}_{1} \mathrm{R}$ strongly positive (Figure 2E). In this study, we confirmed that the MVD number did not correlate with the histological subtype, FIGO stage or histological grade, while VEGF expression scores positively correlated with the MVD number (data not shown). Taken together, our findings indicate that $\mathrm{AT}_{1} \mathrm{R}$, as well as VEGF, are associated with tumour angiogenesis of ovarian carcinoma.

Next, we assessed the correlation between $\mathrm{AT}_{1} \mathrm{R}$ expression and tumour proliferation using immunohistochemical staining with PCNA in the same series of ovarian cancer tissues. The PCNA LI ranged from 16 to $80 \%$, with a mean value of $50.16 \%$, which is well consistent with the results from a previous report (Thomas et al, 1995). We defined cases with a PCNA LI of more than 50 as high PCNA LI $(n=37)$, while cases with a PCNA LI of $<50$ were defined as low PCNA LI $(n=30)$. As shown in Figure $2 \mathrm{~F}$, the $\mathrm{AT}_{1} \mathrm{R}$ expression score did not significantly correlate with PCNA LI.

The results from correlation analyses of $\mathrm{AT}_{1} \mathrm{R}$ overexpression (strongly positive cases) with clinicopathological parameters, VEGF expression, MVD and PCNA are summarized in Table 1. These analyses demonstrated that $\mathrm{AT}_{1} \mathrm{R}$ overexpression was significantly correlated with VEGF overexpression and high MVD number, but not with the proliferation marker PCNA, nor any of the clinicopathological factors examined in this study.

\section{Correlation of $\mathrm{AT}_{1} \mathrm{R}$ expression with survival of ovarian cancer patients}

Follow-up data were available for 58 patients (nine patients were lost to follow-up). The median follow-up was 60 months (range 1-121 months). During the follow-up period, the total number of cases in which death and progression/recurrence were observed was $19(32.8 \%)$ and $25(43.1 \%)$, respectively. 
A

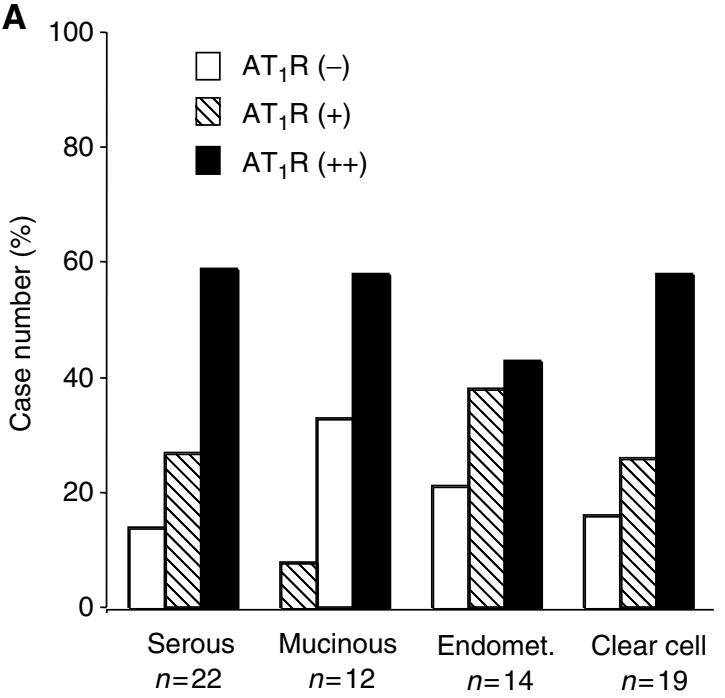

C

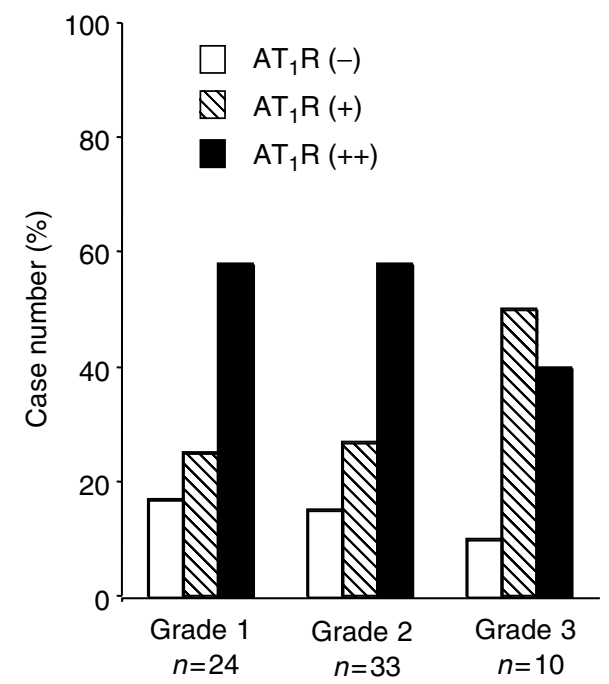

E

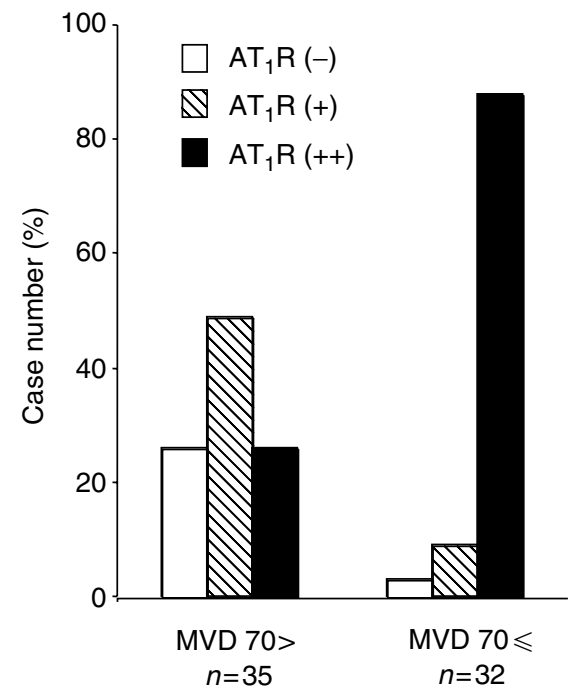

B

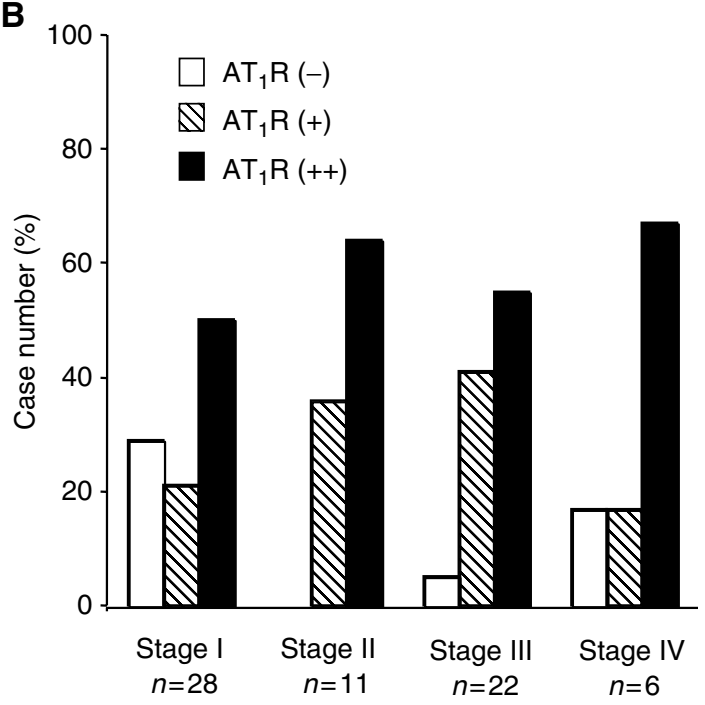

D

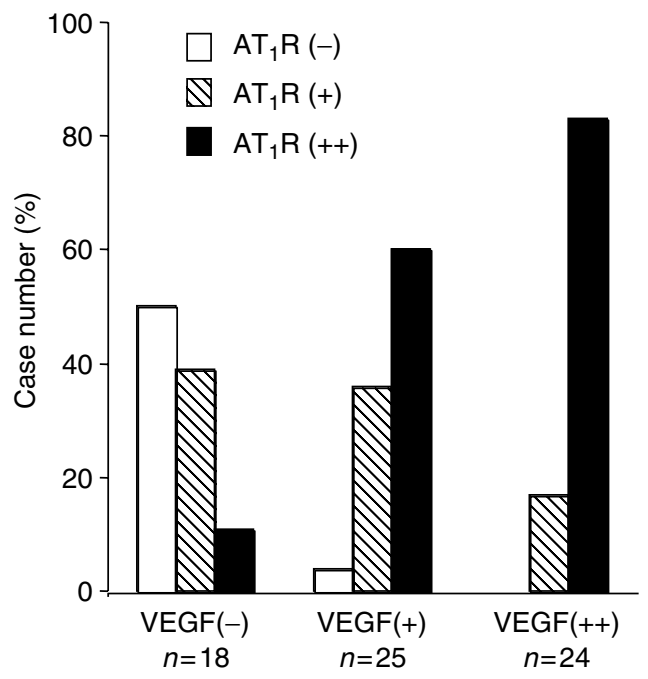

F

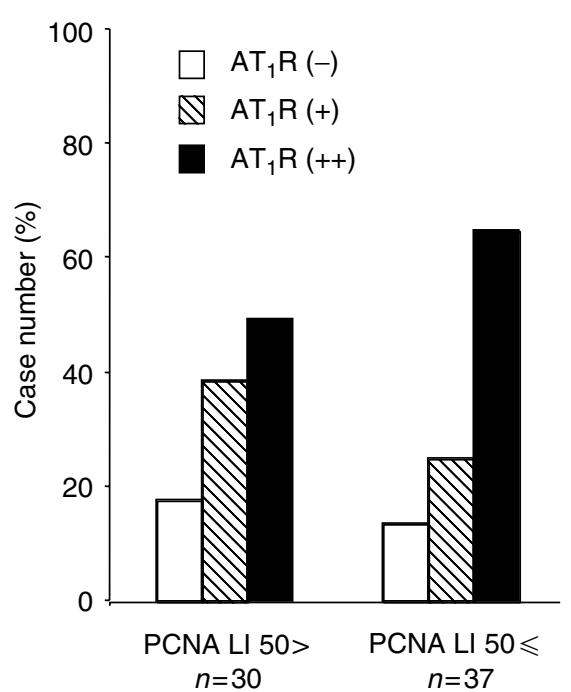

Figure 2 Correlation of AT,R expression intensity with histological subtype (A), FIGO stage (B), histological grade (C), VEGF expression intensity (D), MVD number $(\mathbf{E})$, and PCNA LI $(\mathbf{F})$ in ovarian cancer tissues. Significant correlation $(P<0.05)$ was observed between $A T, R$ expression and VEGF expression (D), or between AT, R expression and MVD number $(\mathbf{E})$, while there was no significant correlation between $A T, R$ expression and other clinicopathological factors or PCNA LI. 
Table I Correlation of $A T, R$ overexpression with clinicopathologic factors, and angiogenesis/proliferation markers in ovarian cancer

\begin{tabular}{|c|c|c|c|c|c|}
\hline & \multicolumn{2}{|c|}{ Patients } & \multicolumn{2}{|c|}{$A T_{1} R$ overexpression } & \multirow[b]{2}{*}{$P$-value } \\
\hline & No. & $\%$ & No. & $\%$ & \\
\hline All cases & 67 & 100.0 & 37 & 55.2 & \\
\hline \multicolumn{6}{|l|}{ Histological type } \\
\hline Serous & 22 & 32.8 & 13 & 59.1 & $0.777^{\mathrm{a}}$ \\
\hline Mucinous & 12 & 17.9 & 7 & 58.3 & \\
\hline Endometrioid & 14 & 20.9 & 6 & 42.9 & \\
\hline Clear cell & 19 & 28.4 & || & 57.9 & \\
\hline \multicolumn{6}{|l|}{ Histological grade } \\
\hline GI & 24 & 35.8 & 14 & 58.3 & $0.576^{\mathrm{a}}$ \\
\hline G2 & 33 & 49.3 & 19 & 57.6 & \\
\hline G3 & 10 & 14.9 & 4 & 40.0 & \\
\hline \multicolumn{6}{|l|}{ FIGO stage } \\
\hline 1 & 28 & 41.8 & 14 & 50.0 & $0.814^{\mathrm{a}}$ \\
\hline$\|$ & | | & 16.4 & 7 & 63.6 & \\
\hline III & 22 & 32.8 & 12 & 54.5 & \\
\hline IV & 6 & 9.0 & 4 & 66.7 & \\
\hline \multicolumn{6}{|l|}{ VEGF expression } \\
\hline$(-)$ & 18 & 26.9 & 2 & $|1|$. & $0.001^{b}$ \\
\hline$(+)$ & 49 & 73.1 & 35 & 71.4 & \\
\hline \multicolumn{6}{|l|}{ Microvessel density } \\
\hline $70>$ & 35 & 52.2 & 9 & 25.7 & $0.001^{b}$ \\
\hline $70 \leqslant$ & 32 & 47.8 & 28 & 87.5 & \\
\hline \multicolumn{6}{|l|}{ PCNA LI } \\
\hline $50>$ & 30 & 44.8 & 14 & 46.7 & $0.205^{b}$ \\
\hline $50 \leqslant$ & 37 & 55.2 & 23 & 62.2 & \\
\hline
\end{tabular}

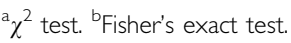

To evaluate the impact of $\mathrm{AT}_{1} \mathrm{R}$ expression on patient prognosis, overall survival (OS) and PFS curves were constructed using the Kaplan-Meier method. The 5-year OS rates of patients who had negative $(n=10)$, weakly positive $(n=18)$, and strongly positive $(n=30)$ expression for $\mathrm{AT}_{1} \mathrm{R}$ were $100,45.8$ and $55.7 \%$, respectively (Figure $3 \mathrm{~A}$ ). The 5-year PFS rates of patients who had negative, weakly positive, and strongly positive expression for $\mathrm{AT}_{1} \mathrm{R}$ were $100,27.5$ and $41.9 \%$, respectively (Figure $3 \mathrm{~B}$ ). Both OS and PFS in patients with positive (weak and strong) expression for $\mathrm{AT}_{1} \mathrm{R}$ were significantly lower than those in patients with negative $\mathrm{AT}_{1} \mathrm{R}$ expression $(P=0.041$ and 0.017 , respectively, by log-rank test). However, there was no significant difference in the distributions of OS and PFS between the $\mathrm{AT}_{1} \mathrm{R}$-weakly positive and $\mathrm{AT}_{1} \mathrm{R}$-strongly positive groups.

The correlation of VEGF expression, intratumour MVD, and PCNA LI with prognosis was also analysed. The 5-year OS rates of patients who had negative $(n=15)$, weakly positive $(n=22)$ and strongly positive $(n=21)$ expression for VEGF were $92.9,48.4$ and $51.3 \%$, respectively (Figure $3 \mathrm{C}$ ). The 5-year PFS rates of patients who had negative, weakly positive and strongly positive expression for VEGF were 69.6, 47.6 and $24.2 \%$, respectively (Figure 3D). Both OS and PFS in patients with positive expression for VEGF were significantly lower than those in patients with negative VEGF expression ( $P=0.046$ and 0.036 , respectively, by log-rank test), although there was no significant difference in the distributions of OS and PFS between the VEGF-weakly positive and strongly positive groups. In contrast to $\mathrm{AT}_{1} \mathrm{R}$ and VEGF, there was no significant difference in the distributions of OS and PFS according to the MVD number ( $P=0.203$ and 0.467 , respectively), or according to the PCNA LI ( $P=0.909$ and 0.316 , respectively), as shown in Figure $3 \mathrm{E}-\mathrm{H}$. These results indicate that $\mathrm{AT}_{1} \mathrm{R}$ and VEGF, but not the MVD number and PCNA LI, significantly correlated with the impaired survival of ovarian cancer patients.

\section{Multivariate analysis of prognostic variables in ovarian cancer patients}

Cox proportional-hazard analysis was performed to determine the impact of various factors on survival. The results of univariate/ multivariate analyses of the variables, including $\mathrm{AT}_{1} \mathrm{R}, \mathrm{VEGF}$, MVD and PCNA LI, with respect to OS and PFS are shown in Tables 2 and 3, respectively. Because none of the patients with negative $\mathrm{AT}_{1} \mathrm{R}$ expression $(n=10)$ died or recurred (no risk for OS and $\mathrm{PFS}$ ), the univariate analysis for $\mathrm{AT}_{1} \mathrm{R}$ expression (negative or weakly/strongly positive) could not be performed, and it was not entered into the multivariate analysis model. Among the other six variables, the FIGO stage $(P=0.025)$ and VEGF expression $(P=0.018)$ were statistically significant prognostic factors with respect to OS on multivariate analysis (Table 2$)$. Similarly, the FIGO stage $(P=0.015)$ and VEGF expression $(P=0.008)$ were found to be independent prognostic factors with respect to PFS on multivariate analysis (Table 3 ).

\section{DISCUSSION}

In the present study, we demonstrated the expression of the type 1 angiotensin II receptor, $\mathrm{AT}_{1} \mathrm{R}$, in human ovarian carcinoma tissues, and its significant correlation with tumour angiogenesis and patient survival. It has been reported that $\mathrm{AT}_{1} \mathrm{R}$ is expressed in various human malignant tumour tissues, including breast cancer (Inwang et al, 1997), skin cancer (Takeda and Kondo, 2001), pancreatic cancer (Fujimoto et al, 2001), laryngeal carcinoma (Marsigliante et al, 1996) and prostate cancer (Uemura et al, 2003). Furthermore, we recently demonstrated that $\mathrm{AT}_{1} \mathrm{R}$ was expressed in gynaecological malignancies, including cervical cancer (Kikkawa et al, 2004), endometrial cancer (Watanabe et al, 2003), choriocarcinoma (Ino et al, 2003), and ovarian cancer (Suganuma et al, 2005). These findings suggest that $\mathrm{AT}_{1} \mathrm{R}$ exists in a wide spectrum of human cancers, especially in gynaecological malignancies, and that the angiotensin II- $\mathrm{AT}_{1} \mathrm{R}$ system may play significant roles in the localized RAS within these tumour tissues. Evidence for the involvement of $\mathrm{AT}_{1} \mathrm{R}$ in tumour progression, such as growth, metastasis and angiogenesis, has accumulated in various animal models (Rivera et al, 2001; Fujita et al, 2002; Miyajima et al, 2002; Egami et al, 2003; Uemura et al, 2003; Arrieta et al, 2005). Until now, however, there have been no reports analysing the correlation of $\mathrm{AT}_{1} \mathrm{R}$ expression with clinical parameters, especially with patient prognosis, using a large scale of clinical samples of human cancers. Thus, the present study is the first to investigate the correlation between $\mathrm{AT}_{1} \mathrm{R}$ and clinical outcome in ovarian cancer patients.

Our immunohistochemical analysis showed that $\mathrm{AT}_{1} \mathrm{R}$ was present in $85 \%$ of ovarian carcinomas examined, and it was overexpressed in more than half $(55 \%)$ of the cases. Furthermore, $\mathrm{AT}_{1} \mathrm{R}$ expression was not dependent on the histological subtype, grade or FIGO stage, although the rate of $\mathrm{AT}_{1} \mathrm{R}$-negative cases was relatively high in FIGO stage I (eight of 28 cases: $29 \%$ ) as compared to those in FIGO II-IV. Our prior studies showed that $A T_{1} R$ expression was almost absent in benign ovarian cystadenoma, but was dramatically upregulated with progression from borderline malignancy to invasive ovarian carcinoma (Suganuma et al, 2005). These results suggest the possible involvement of $A T_{1} R$ in the specific cell behaviours that were common to the malignant phenotypes, such as tumour cell invasion or aggressive neovascularization, rather than in the degree of tumour differentiation or histopathological subtypes. 

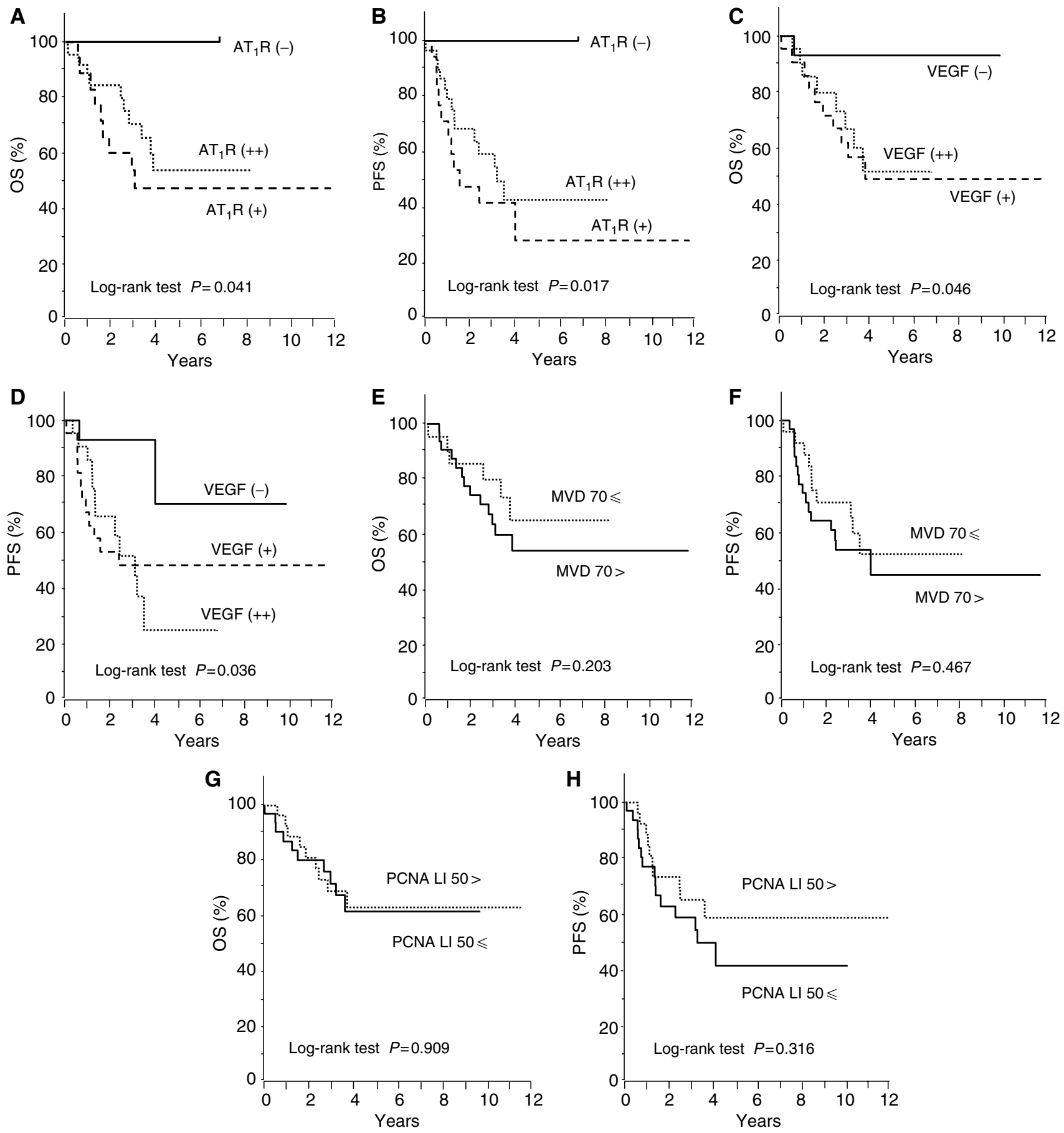

Figure 3 Overall survival (OS) and progression-free survival (PFS) curves drawn using the Kaplan-Meier method according to the AT,R expression (A and B), VEGF expression ( $\mathbf{C}$ and $\mathbf{D})$, MVD number $(\mathbf{E}$ and $\mathbf{F})$, and PCNA LI (G and $\mathbf{H})$. Significant differences in the OS and PFS according to the AT,R expression $(P=0.041$ and 0.017 , respectively), and according to the VEGF expression $(P=0.046$ and 0.036 , respectively). No significant difference in the OS and PFS according to the MVD $(P=0.203$ and 0.467, respectively) and according to the PCNA LI $(P=0.909$ and 0.316 , respectively).

It is of particular interest that $\mathrm{AT}_{1} \mathrm{R}$ expression was positively correlated with VEGF expression intensity in the ovarian carcinomas examined in this study. Vascular endothelial growth factor is known to be the main angiogenic factor in ovarian cancer (Yamamoto et al, 1997; Fujimoto et al, 1998; Bamberger and Perrett, 2002). It has been shown that angiotensin II upregulated VEGF expression via $\mathrm{AT}_{1} \mathrm{R}$ (Chua et al, 1998; Pupilli et al, 1999; Tamarat et al, 2002), and this angiotensin II-induced VEGF upregulation was mediated by hypoxia-inducible factor-1, even in non-hypoxic conditions (Richard et al, 2001). We have recently reported that angiotensin II stimulated VEGF expression and secretion in $\mathrm{AT}_{1} \mathrm{R}$-positive ovarian cancer cells in vitro (Suganuma et al, 2005). Furthermore, we found that ACE, an enzyme producing angiotensin II in the RAS, was expressed in the tumour stroma of ovarian cancer (data not shown). Thus, the positive correlation between $\mathrm{AT}_{1} \mathrm{R}$ and VEGF observed in the present study 
Table 2 Univariate and multivariate analyses of overall survival (OS) in ovarian cancer patients

\begin{tabular}{|c|c|c|c|c|c|c|c|}
\hline \multirow[b]{2}{*}{ Variables } & \multirow[b]{2}{*}{ Categories } & \multicolumn{2}{|c|}{ Univariate analysis } & \multirow[b]{2}{*}{$P$-value } & \multicolumn{2}{|c|}{ Multivariate analysis } & \multirow[b]{2}{*}{$P$-value } \\
\hline & & Hazard ratio & $95 \% \mathrm{Cl}$ & & Hazard ratio & $95 \% \mathrm{Cl}$ & \\
\hline Histological grade & $\begin{array}{l}1 \text { or } 2 \\
3\end{array}$ & 0.19 & $0.02-1.56$ & 0.122 & 0.22 & $0.03-1.71$ & 0.147 \\
\hline ATIR overexpression & $\begin{array}{l}(-) /(+) \\
(++)\end{array}$ & 0.86 & $0.25-2.98$ & 0.815 & - & - & - \\
\hline VEGF expression & $\begin{array}{l}(-) \\
(+) /(++)\end{array}$ & 5.75 & $0.71-46.52$ & 0.101 & 12.18 & $1.54-96.37$ & 0.018 \\
\hline
\end{tabular}

$\mathrm{Cl}=$ confidence interval. ${ }^{a} \mathrm{ND}=$ not determined because no patients with negative ATIR expression died or recurred.

Table 3 Univariate and multivariate analyses of progression-free survival (PFS) in ovarian cancer patients

\begin{tabular}{|c|c|c|c|c|c|c|c|}
\hline \multirow[b]{2}{*}{ Variables } & \multirow[b]{2}{*}{ Categories } & \multicolumn{2}{|c|}{ Univariate analysis } & \multirow[b]{2}{*}{$P$-value } & \multicolumn{2}{|c|}{ Multivariate analysis } & \multirow[b]{2}{*}{$P$-value } \\
\hline & & Hazard ratio & $95 \% \mathrm{Cl}$ & & Hazard ratio & $95 \% \mathrm{Cl}$ & \\
\hline Histological grade & $\begin{array}{l}1 \text { or } 2 \\
3\end{array}$ & 0.58 & $0.16-2.08$ & 0.400 & - & - & - \\
\hline ATIR overexpression & $\begin{array}{l}(-) /(+) \\
(++)\end{array}$ & 0.85 & $0.26-2.75$ & 0.789 & - & - & - \\
\hline VEGF expression & $\begin{array}{l}(-) \\
(+) /(++)\end{array}$ & 4.10 & $0.88-19.02$ & 0.072 & 7.49 & $1.68-33.32$ & 0.008 \\
\hline
\end{tabular}

$\mathrm{Cl}=$ confidence interval. ${ }^{\mathrm{N}} \mathrm{ND}=$ not determined because no patients with negative ATIR expression died or recurred.

not only reflects the results from the prior in vitro studies, but also suggests the existence of the angiotensin II-AT ${ }_{1} \mathrm{R}-\mathrm{VEGF}$ system controlling angiogenic signals in ovarian cancer.

In addition to VEGF, the intratumour MVD number also positively correlated with $\mathrm{AT}_{1} \mathrm{R}$ expression intensity. Indeed, $\mathrm{AT}_{1} \mathrm{R}$ was overexpressed in $87.5 \%$ of the cases with high MVD numbers (more than 70). It is well known that MVD is a most reliable tool for reflecting tumour angiogenesis (Weidner et al, 1992) and it has been reported that VEGF expression directly correlated with increased MVD in a variety of tumours (Toi et al, 1996; Maeda et al, 1996). In the present study, we found the positive correlation of MVD number not only with VEGF, but also with $\mathrm{AT}_{1} \mathrm{R}$. These findings support our hypothesis that $\mathrm{AT}_{1} \mathrm{R}$ is a key molecule in tumour angiogenesis in ovarian cancer.

It has been reported that $\mathrm{AT}_{1} \mathrm{R}$ is involved in the proliferation of various cancers in vitro and in vivo (Fujimoto et al, 2001; Rivera et al, 2001; Muscella et al, 2002; Ino et al, 2003; Uemura et al, 2003). However, our immunohistochemical study showed that the $\mathrm{AT}_{1} \mathrm{R}$ expression score did not significantly correlate with the positivity of the cellular proliferation marker PCNA in ovarian cancer tissues. Consistently, we previously reported that angiotensin II enhanced the invasive activity and VEGF secretion, but not cell proliferation, in $\mathrm{AT}_{1} \mathrm{R}$-positive ovarian cancer cell lines in vitro (Suganuma et al, 2005). Taken together, it appears that 
$\mathrm{AT}_{1} \mathrm{R}$ is not directly involved in tumour cell proliferation in ovarian cancer, and that the angiotensin II- $\mathrm{AT}_{1} \mathrm{R}$ system plays differential roles in cancer progression, which may be dependent upon tumour type.

Our results from survival analyses demonstrated that both OS and PFS were significantly poorer in $\mathrm{AT}_{1} \mathrm{R}$-positive cases than those in $\mathrm{AT}_{1} \mathrm{R}$-negative cases. This provides the first evidence for the positive correlation of $\mathrm{AT}_{1} \mathrm{R}$ expression with poor clinical outcome in human malignancies. Surprisingly, we observed $100 \%$ of the 5-year OS and PFS in $\mathrm{AT}_{1} \mathrm{R}$-negative cases, although the case number of these $\mathrm{AT}_{1} \mathrm{R}$-non-expressing ovarian carcinomas was small $(n=10)$ in this study. In addition, we showed that there was no significant difference in the survival between $\mathrm{AT}_{1} \mathrm{R}$ strongly positive and weakly positive within the $\mathrm{AT}_{1} \mathrm{R}$-expressing cases. These results might be unexpected because the immunohistochemical analysis showed a clear correlation between overexpression (strongly positive) of $\mathrm{AT}_{1} \mathrm{R}$ with high VEGF expression and high MVD numbers. One could speculate that the existence (either high or low expression) of $\mathrm{AT}_{1} \mathrm{R}$ plays a crucial role in the initiation of angiogenic signals in the primary lesions of ovarian cancer, while other various molecules are complexly involved in subsequent tumour progression, such as peritoneal dissemination or distal metastasis. Similar to $\mathrm{AT}_{1} \mathrm{R}$, both the $\mathrm{OS}$ and PFS in VEGF-positive cases were significantly poorer than those in VEGFnegative cases, which is consistent with the observation in previous studies (Yamamoto et al, 1997; Shen et al, 2000). These findings suggest that $\mathrm{AT}_{1} \mathrm{R}$, as well as VEGF, may become a prognostic marker for ovarian cancer patients; however, our multivariate analyses showed that FIGO stage and VEGF, but not $\mathrm{AT}_{1} \mathrm{R}$, were independent prognostic factors for both OS and PFS. These results may be due, at least in part, to the small number of patient samples, because the $\mathrm{AT}_{1} \mathrm{R}$-negative group consisted of only 10 patients, and there was no death or recurrence in this group. Further studies, including multivariate analyses using a larger sample size, are required to clarify whether $\mathrm{AT}_{1} \mathrm{R}$ can be an independent prognostic factor or not.

\section{REFERENCES}

Arrieta O, Guevara P, Escobar E, Garcia-Navarrete R, Pineda B, Sotelo J (2005) Blockage of angiotensin II type I receptor decreases the synthesis of growth factors and induces apoptosis in C6 cultured cells and C6 rat glioma. $\mathrm{Br}$ J Cancer 92: $1247-1252$

Bamberger ES, Perrett CW (2002) Angiogenesis in epithelian ovarian cancer. Mol Pathol 55: 348 - 359

Chi DS, Liao JB, Leon LF, Venkatraman ES, Hensley ML, Bhaskaran D, Hoskins WJ (2001) Identification of prognostic factors in advanced epithelial ovarian carcinoma. Gynecol Oncol 82: 532-537

Chua CC, Hamdy RC, Chua BH (1998) Upregulation of vascular endothelial growth factor by angiotensin II in rat heart endothelial cells. Biochim Biophys Acta 1401: 187-194

Egami K, Murohara T, Shimada T, Sasaki K, Shintani S, Sugaya T, Ishii M, Akagi T, Ikeda H, Matsuishi T, Imaizumi $\mathrm{T}$ (2003) Role of host angiotensin II type 1 receptor in tumor angiogenesis and growth. J Clin Invest 112: $67-75$

Fujimoto J, Sakaguchi H, Hirose R, Ichigo S, Tamaya T (1998) Biologic implications of the expression of vascular endothelial growth factor subtypes in ovarian carcinoma. Cancer 83: 2528-2533

Fujimoto Y, Sasaki T, Tsuchida A, Chayama K (2001) Angiotensin II type 1 receptor expression in human pancreatic cancer and growth inhibition by angiotensin II type 1 receptor antagonist. FEBS Lett 495: 197-200

Fujimura H, Ino K, Nagasaka T, Nakashima N, Nakazato H, Kikkawa F, Mizutani S (2000) Aminopeptidase A expression in cervical neoplasia and its relationship to neoplastic transformation and progression. Oncology 58: $342-352$

Fujita M, Hayashi I, Yamashina S, Itoman M, Majima M (2002) Blockade of angiotensin AT1a receptor signaling reduces tumor growth, angiogenesis, and metastasis. Biochem Biophys Res Commun 294: 441 - 447
In contrast to $\mathrm{AT}_{1} \mathrm{R}$ and VEGF, our study demonstrated that there was no significant difference in the survival according to the MVD number or PCNA LI. Previous studies showed that MVD was not a useful prognostic factor in ovarian cancer (Obermair et al, 1999; Shen et al, 2000; Bamberger and Perrett, 2002). On the other hand, Hollingsworth et al (1995) reported that MVD was significantly correlated with poor prognosis of advanced stage ovarian cancer, while conversely it was associated with better prognosis (Ogawa et al, 2002). Correlation of the cellular proliferation marker index, such as PCNA and Ki-67, with patient survival is also controversial in ovarian cancer (Nakopoulou et al, 1993; Thomas et al, 1995; Itamochi et al, 2002). The reason for these controversial findings remains unclear, but may be due at least in part to the complicated mechanisms for tumour angiogenesis and growth of ovarian cancer that are differentially regulated among the histological subtypes (Bamberger and Perrett, 2002).

In summary, we demonstrated that $\mathrm{AT}_{1} \mathrm{R}$ expression was associated with tumour angiogenesis of ovarian cancer and also correlated with poor patient outcome. There has been accumulated evidence that $\mathrm{AT}_{1} \mathrm{R}$ blockade therapy suppresses tumour growth, metastasis and angiogenesis in experimental animal models (Rivera et al, 2001; Fujita et al, 2002; Miyajima et al, 2002; Egami et al, 2003; Uemura et al, 2003; Arrieta et al, 2005), and we also demonstrated that an $\mathrm{AT}_{1} \mathrm{R}$ blocker suppressed the peritoneal dissemination of ovarian cancer in a mouse model (Suganuma et al, 2005). Combined with these findings, the present data suggest that $\mathrm{AT}_{1} \mathrm{R}$ has clinical potential not only as a prognostic indicator, but also as a novel molecular target in strategies for ovarian cancer treatment.

\section{ACKNOWLEDGEMENTS}

This work was supported in part by grant-in-aid No.15591742 (to KI) from the Japanese Ministry of Education, Culture, Sports, Science and Technology.

Hollingsworth HC, Kohn EC, Steinberg SM, Rothenberg ML, Merino MJ (1995) Tumor angiogenesis in advanced stage ovarian carcinoma. Am J Pathol 147: $33-41$

Ino K, Uehara C, Kikkawa F, Kajiyama H, Shibata K, Suzuki T, Khin EE, Ito M, Takeuchi M, Itakura A, Mizutani S (2003) Enhancement of aminopeptidase A expression during angiotensin II-induced choriocarcinoma cell proliferation through AT1 receptor involving protein kinase $\mathrm{C}$ - and mitogen-activated protein kinase-dependent signaling pathway. J Clin Endocrinol Metab 88: 3973-3982

Inwang ER, Puddefoot JR, Brown CL, Goode AW, Marsigliante S, Ho MM, Payne JG, Vinson GP (1997) Angiotensin II type 1 receptor expression in human breast tissues. Br J Cancer 75: 1279-1283

Itamochi H, Kigawa J, Sugiyama T, Kikuchi Y, Suzuki M, Terakawa N (2002) Low proliferation activity may be associated with chemoresistance in clear cell carcinoma of the ovary. Obstet Gynecol 100: 281-287

Juillerat-Jeanneret L, Celerier J, Chapuis Bernasconi C, Nguyen G, Wostl W, Maerki HP, Janzer RC, Corvol P, Gasc JM (2004) Renin and angiotensinogen expression and functions in growth and apoptosis of human glioblastoma. $\mathrm{Br}$ J Cancer 90: 1059-1068

Kikkawa F, Mizuno M, Shibata K, Kajiyama H, Morita T, Ino K, Nomura S, Mizutani S (2004) Activation of invasiveness of cervical carcinoma cells by angiotensin II. Am J Obstet Gynecol 190: 1258-1263

Le Noble FA, Schreurs NH, van Straaten HW, Slaaf DW, Smits JF, Rogg H, Struijker-Boudier HA (1993) Evidence for a novel angiotensin II receptor involved in angiogenesis in chick embryo chorioallantoic membrane. Am J Physiol 264: R460-465

Maeda K, Chung YS, Ogawa Y, Takatsuka S, Kang SM, Ogawa M, Sawada T, Sowa M (1996) Prognostic value of vascular endothelial growth factor expression in gastric carcinoma. Cancer 77: 858-863 
Marsigliante S, Resta L, Muscella A, Vinson GP, Marzullo A, Storelli C (1996) AT1 angiotensin II receptor subtype in the human larynx and squamous laryngeal carcinoma. Cancer Lett 110: 19-27

McGuire Jr WP, Markman M (2003) Primary ovarian cancer chemotherapy: current standards of care. Br J Cancer 89(Suppl 3): S3 - S8

Miyajima A, Kosaka T, Asano T, Asano T, Seta K, Kawai T, Hayakawa M (2002) Angiotensin II type I antagonist prevents pulmonary metastasis of murine renal cancer by inhibiting tumor angiogenesis. Cancer Res 62: $4176-4179$

Muscella A, Greco S, Elia MG, Storelli C, Marsigliante S (2002) Angiotensin II stimulation of $\mathrm{Na}+\mathrm{K}+\mathrm{ATPase}$ activity and cell growth by calciumindependent pathway in MCF-7 breast cancer cells. J Endocrinol 173: $315-323$

Nakopoulou L, Janinis J, Panagos G, Comin G, Davaris P (1993) The immunohistochemical expression of proliferating cell nuclear antigen (PCNA/cyclin) in malignant and benign epithelial ovarian neoplasms and correlation with prognosis. Eur J Cancer 29A: 1599-1601

Nielsen AH, Hagemann A, Poulsen K (1995) The tissue renin-angiotensin system in the female reproductive tissues: a review. Adv Exp Med Bio 377: $253-268$

Obermair A, Wasicky R, Kaider A, Preyer O, Losch A, Leodolter S, Kolbl H (1999) Prognostic significance of tumor angiogenesis in epithelial ovarian cancer. Cancer Lett 138: $175-182$

Ogawa S, Kaku T, Kobayashi H, Hirakawa T, Ohishi Y, Kinukawa N, Nakano H (2002) Prognostic significance of microvessel density, vascular cuffing and vascular endothelial growth factor expression in ovarian carcinoma: a special review for clear cell adenocarcinoma. Cancer Lett 176: $111-118$

Omura GA, Brady MF, Homesley HD, Yordan E, Major FJ, Buchsbaum HJ, Park RC (1991) Long-term follow-up and prognostic factor analysis in advanced ovarian carcinoma: the Gynecologic Oncology Group experience. J Clin Oncol 9: $1138-1150$

Pupilli C, Lasagni L, Romagnani P, Bellini F, Mannelli M, Misciglia N, Mavilia C, Vellei U, Villari D, Serio M (1999) Angiotensin II stimulates the synthesis and secretion of vascular permeability factor/vascular endothelial growth factor in human mesangial cells. J Am Soc Nephrol 10: 245-255

Richard DE, Vouret-Craviari V, Pouyssegur J (2001) Angiogenesis and Gprotein-coupled receptors: signals that bridge the gap. Oncogene 20: $1556-1562$

Rivera E, Arrieta O, Guevara P, Duarte-Rojo A, Sotelo J (2001) AT1 receptor is present in glioma cells; its blockage reduces the growth of rat glioma. Br J Cancer 85: $1396-1399$

Shen GH, Ghazizadeh M, Kawanami O, Shimizu H, Jin E, Araki T, Sugisaki Y (2000) Prognostic significance of vascular endothelial growth factor expression in human ovarian carcinoma. Br J Cancer 83: 196-203

Shiraishi S, Nakagawa K, Kinukawa N, Nakano H, Sueishi K (1996) Immunohistochemical localization of vascular endothelial growth factor in the human placenta. Placenta 17: 111-121
Suganuma T, Ino K, Shibata K, Kajiyama $\mathrm{H}$, Nagasaka T, Mizutani S, Kikkawa F (2005) Functional expression of the angiotensin II type 1 receptor in human ovarian carcinoma cells and its blockade therapy resulting in suppression of tumor invasion, angiogenesis, and peritoneal dissemination. Clin Cancer Res 11: 2686-2694

Suganuma T, Ino K, Shibata K, Nomura S, Kajiyama H, Kikkawa F, Tsuruoka N, Mizutani S (2004) Regulation of aminopeptidase A expression in cervical carcinoma: role of tumor-stromal interaction and vascular endothelial growth factor. Lab Invest 84: 639-648

Takeda H, Kondo S (2001) Differences between squamous cell carcinoma and keratoacanthoma in angiotensin type-1 receptor expression. Am J Pathol 158: $1633-1637$

Tamarat R, Silvestre JS, Durie M, Levy BI (2002) Angiotensin II angiogenic effect in vivo involves vascular endothelial growth factor- and inflammation-related pathways. Lab Invest 82: 747 - 756

Thomas H, Nasim MM, Sarraf CE, Alison MR, Love S, Lambert HE, Price P (1995) Proliferating cell nuclear antigen (PCNA) immunostaining -a prognostic factor in ovarian cancer? Br J Cancer 71: $357-362$

Toi M, Kondo S, Suzuki H, Yamamoto Y, Inada K, Imazawa T, Taniguchi T, Tominaga T (1996) Quantitative analysis of vascular endothelial growth factor in primary breast cancer. Cancer 77: $1101-1106$

Ueda M, Terai Y, Kumagai K, Ueki K, Okamoto Y, Ueki M (1999) Correlation between tumor angiogenesis and expression of thymidine phosphorylase, and patient outcome in uterine cervical carcinoma. $\mathrm{Hum}$ Pathol 30: $1389-1394$

Uemura $\mathrm{H}$, Ishiguro $\mathrm{H}$, Nakaigawa $\mathrm{N}$, Nagashima $\mathrm{Y}$, Miyoshi $\mathrm{Y}$, Fujinami K, Sakaguchi A, Kubota Y (2003) Angiotensin II receptor blocker shows antiproliferative activity in prostate cancer cells: a possibility of tyrosine kinase inhibitor of growth factor. Mol Cancer Ther 2: 1139 - 1147

Watanabe Y, Shibata K, Kikkawa F, Kajiyama H, Ino K, Hattori A, Tsujimoto M, Mizutani S (2003) Adipocyte-derived leucine aminopeptidase suppresses angiogenesis in human endometrial carcinoma via renin-angiotensin system. Clin Cancer Res 9: 6497-6503

Weidner N, Folkman J, Pozza F, Bevilacqua P, Allred EN, Moore DH, Meli S, Gasparini G (1992) Tumor angiogenesis: a new significant and independent prognostic indicator in early-stage breast carcinoma. J Natl Cancer Inst 84: $1875-1887$

Yamamoto S, Konishi I, Mandai M, Kuroda H, Komatsu T, Nanbu K, Sakahara H, Mori T (1997) Expression of vascular endothelial growth factor (VEGF) in epithelial ovarian neoplasms: correlation with clinicopathology and patient survival, and analysis of serum VEGF levels. Br J Cancer 76: $1221-1227$

Yoshiji H, Kuriyama S, Kawata M, Yoshiji J, Ikenaka Y, Noguchi R, Nakatani T, Tsujinoue H, Fukui H (2001) The angiotensin-I-converting enzyme inhibitor perindopril suppresses tumor growth and angiogenesis: possible role of the vascular endothelial growth factor. Clin Cancer Res 7: 1073-1078 